\title{
Mindfulness moments for clinicians in the midst of a pandemic
}

\author{
E. Hedderman ${ }^{1 * *}$, V. O'Doherty ${ }^{2}$ and S. $\mathrm{O}^{\prime}$ Connor $^{2}$ \\ ${ }^{1}$ Lucena Clinic, Dublin, Ireland \\ ${ }^{2}$ Department of Psychology, Tallaght University Hospital, Dublin, Ireland
}

\begin{abstract}
Clinicians are routinely subjected to intense and stressful working environments, and the current COVID-19 crisis increases their risk of psychological distress. Mindfulness has been shown to improve life satisfaction, resilience to stress, self-compassion, compassion and general well-being in healthcare workers. Based on their clinical experience, the authors present mindfulness moments for clinicians (MMFC), a selection of short, simple and accessible mindfulness practices to promote resilience and compassion among clinicians working in this pandemic. The practices can be used on the job and are accessible to both novice and experienced meditators. Most of these practices are extracted from evidence-based mindfulness programmes. Further research is indicated to assess the effectiveness of using MMFC to support clinicians in their work and to promote resilience.
\end{abstract}

Received 20 April 2020; Revised 13 May 2020; Accepted 16 May 2020; First published online 21 May 2020

Key words: Clinicians, compassion, COVID-19, mindfulness, pandemic.

\section{Getting Grounded.}

On your inbreath, gather your attention.

On your outbreath, drop into the body.

Shift your attention to the sensation of your feet on the floor.

Sense stability and support through this connection to the earth.

Rest in the experience of being grounded. Joan Halifax (Halifax, 2020)

\section{Introduction}

Looking after the health of people provides many rewards but brings significant challenges. During a crisis, such as the current COVID-19 pandemic, these challenges can substantially increase. Healthcare workers are routinely subjected to intense stimuli in their work that may lead to burnout (Chernoff et al. 2018) and result in distress and emotional suffering (Ducar et al. 2020). In this current unprecedented global pandemic, front-line healthcare workers are risking their lives in the line of duty requiring them to demonstrate courage in the presence of fear.

A systematic Cochrane review (Ruotsalainen et al. 2014) reported that healthcare workers face high expectations, insufficient time allowance to fulfil those expectations, poor skills to manage stress-provoking stimuli and low social support at work when the stress response is triggered. This leads to symptoms of burnout, physical illness, an inability to provide high-quality

\footnotetext{
*Address for correspondence: E. Hedderman, Lucena Clinic, 59 Orwell Road, Rathgar, Dublin 6, Ireland

(Email: elmahedderman@gmail.com)
}

healthcare services and increased cost to the individual and governing body due to sick leave and high staff turnover rates.

During the Ebola outbreak in 2014, front-line workers were also coping with an imminent threat to their lives, working excessive hours, fear of contamination for themselves and loved ones, the breakdown of social support systems, the deaths of colleagues and increased psychological distress (Lehmann et al. 2015). They were also at risk of developing psychological symptoms such as obsession-compulsion, interpersonal sensitivity, depression and paranoid ideation (Ji et al. 2017).

In the 2014 Middle Eastern MERS-CoV infection, healthcare workers experienced 'emotional turmoil' during their duty (Khalid et al. 2016: 8). Similarly with the severe acute respiratory syndrome (SARS) outbreak in China (Ji et al. 2017), 89\% of healthcare workers in high-risk situations reported psychological symptoms (Chua et al. 2004). Nurses experienced fear of dying, feelings of isolation, loneliness, need for support and fear of exposing family members to the virus. Healthcare workers on the front line of the SARS outbreak were at risk of developing psychological distress. The psychological distress for SARS survivors appeared to be 'substantial, pervasive and long-lasting' (Gardner and Moallef, 2015: 133).

In the current COVID-19 outbreak in China, a significant proportion of healthcare workers experienced anxiety, depression and insomnia symptoms. More than $70 \%$ reported psychological distress. Specifically women, nurses and front-line healthcare workers had a high risk of developing unfavourable mental health 
outcomes and may require psychological support or intervention (Lai et al. 2020).

As COVID-19 spreads globally, healthcare workers are increasingly vulnerable to psychological distress. Government and healthcare systems have a responsibility to develop a range of supports to address this. Good management, feeling safe at work generally, having supportive colleagues and a positive atmosphere are also necessary components (Khalid et al. 2016). Drawing on our clinical experience and mindfulness practice, this paper will present a mindfulness tool that may be used by clinicians on the job.

\section{Mindfulness in clinical settings}

Mindfulness can be defined as the awareness that emerges through paying attention on purpose, in the present moment and non-judgmentally to the unfolding of experience moment by moment (KabatZinn, 2003). Mindfulness training for healthcare staff can promote self-care and well-being (Irving et al. 2009). Increases in self-compassion as a result of mindfulness programmes are particularly relevant to professional caregivers (Shapiro et al. 2007). Compassion for both self and others in a clinical setting is a necessary component to facilitating a therapeutic environment (Gilbert, 2005). Research demonstrates that by being compassionate and kind to ourselves and others we can help settle our feelings. 'We can work on whatever problems we need to work on - from an understanding, kind and compassionate position' (Gilbert, 2010: 31).

Growing research evidence shows the benefits of mindfulness on healthcare worker's life satisfaction (Lomas et al. 2018), resilience to stress (Kinser et al. 2016), professional quality of life (Keogh et al. 2019), self-compassion (Wasson et al. 2020), trait mindfulness, compassion and general well-being (Ducar et al. 2020). The impact of a modified version of mindfulness-based stress reduction (MBSR) for emergency healthcare workers was specifically explored (Ducar et al. 2020).

Mindfulness is the foundation of self-compassion insofar as we can only respond self-compassionately when we know we are struggling (McGehee et al. 2017). Self-compassionate people react to adverse events in a more emotionally regulated pattern. Their responses are less extreme with less focus on negative affect and with more self-acceptance and an internal locus of control (Leary et al. 2007). Self-compassion is associated with a range of psychological strengths such as resilience, happiness, optimism, wisdom, curiosity, courage, exploration and emotional intelligence (Germer and Neff, 2013). Often people who are self-critical believe that without their inner critic, they will no longer be motivated to achieve their goals. However, research indicates that self-compassion can enhance motivation towards goal achievement and can facilitate soothing of maladaptive perfectionism (Neff, 2003).

A mindful self-compassion programme called Cultivate Your Inner Resilience (CYIR) was adapted from the Mindful Self-Compassion (MSC) programme (Neff et al. 2013) for healthcare workers in Ireland (Keogh et al. 2019). Significant improvements were found in stress, secondary traumatic stress and selfcompassion immediately following the intervention. At a 6-month follow-up, self-compassion improvement had maintained. People with self-compassionate qualities are less self-critical and less likely to suffer with mental health issues (Beaumont et al. 2016). They have greater emotional regulation and resilience, are more capable of coping with stress and are less at risk of compassion fatigue and burnout (Thompson et al. 2014).

\section{Mindfulness moments for clinicians}

Based on the clinical experience of the authors, we have highlighted several mindfulness practices that may be utilised by clinicians. These mindfulness moments for clinicians (MMFC) have been highlighted in supplementary Tables 1 and 2. MMFC may be used to support clinicians and promote resilience in the midst of a pandemic. All of our chosen practices are short and can be easily used by both frequent meditators and those who are new to the practice. Most importantly, they can be used 'on the job'. MMFC incorporates evidence-based mindfulness practices for healthcare workers. Most of the practices have been extracted directly from the following evidencebased 8-week programmes: MSC (Neff et al. 2013), MBSR (Kabat-Zinn, 1990) and mindfulness-based cognitive therapy (MBCT) programmes (Segal et al. 2002). The RAIN (Recognise, Allow, Investigate and Nurture) practice stems from the work of mediation teacher Tara Brach (Brach, 2020). She refers to it as the 'RAIN of SelfCompassion'. The acronym was first coined about 20 years ago by Michele McDonald. The GRACE practice has five elements: (1) Gathering attention: focus, grounding, balance. (2) Recalling intention: the resource of motivation. (3) Attuning to self/other: affective resonance. (4) Considering: what will serve. (5) Engaging: ethical enactment, then ending. Joan Halifax, a Buddhist teacher and anthropologist, developed the practice from her work on compassion in clinical care settings (Halifax, 2012). Gratitude meditation is strongly related to wellbeing (Emmons et al. 2003; Wood et al. 2010; O'Leary et al. 2015; Sirois et al. 2017). We have provided a gratitude practice by Tara Brach (Brach, 2017). Savouring meditation can greatly increase happiness and life satisfaction (Bryant \& Veroff, 2007). The savouring practice provided is from the Greater Good Science Centre at the University of California, Berkeley. 
To use the MMFC (supplementary Table 1), click the hyperlink to listen to or read the practice. See supplementary Table 2 for the authors' modified version of these practices.

\section{Conclusion}

Healthcare workers are at risk of psychological distress and burnout during their routine work. During this unprecedented pandemic, there is potential for this to be significantly exacerbated. Mindfulness has been shown to improve healthcare worker's life satisfaction, resilience to stress, professional quality of life, selfcompassion, trait mindfulness, compassion and general well-being. MMFC (supplementary Table 1) practices have the potential to support clinicians whenever they feel overwhelmed at work. These are short practices and easy to remember. By paying attention and noticing how they feel physically and psychologically, clinicians will be better able to recognise and meet their own needs. Compassion and self-compassion within the MFFC can also give comfort to the body and the mind affirming that courage is not absence of fear, but the willingness to be present and respond with equanimity in spite of it. MMFC is a simple and straightforward tool that may be easily incorporated into staff support training. Whilst the research indicates that mindfulness can help psychological distress in healthcare workers, it is only one tool. Governments and organisations have a responsibility to provide a range of other supports for healthcare workers. Further research is warranted to determine the effectiveness of using MMFC as it could potentially provide a pathway for clinicians to deepen their self-care through awareness of their body and mental state when providing care to their patients.

\section{Conflict of interest}

The authors have no conflict of interest to disclose.

\section{Ethical Standards}

The author asserts that all procedures contributing to this work comply with the ethical standards of the relevant national and institutional committee on human experimentation with the Helsinki Declaration of 1975, as revised in 2008. The authors assert that ethical approval was not required for publication of this paper.

\section{Financial Support}

This article received no specific grant from any funding agency, commercial or not-for-profit sectors.

\section{Supplementary material}

To view supplementary material for this article, please visit https:/ / doi.org/10.1017/ipm.2020.59

\section{References}

Beaumont E, Durkin M, Hollins Martin C, Carson J (2016)

Measuring relationships between self-compassion, compassion fatigue, burnout and well-being in student counsellors and student cognitive behavioural psychotherapists: a quantitative survey. Counselling and Psychotherapy Research 16, 15-23.

Brach T (2015) Meditation: the RAIN of self-compassion. Guided Meditations (https://www.tarabrach.com/meditationthe-rain-of-self-compassion/). Accessed 8 May 2020.

Brach T (2017) Tara Talks - Reflection: The Practice of Gratitude as a Gateway to Happiness (https://www. youtube.com/watch?v=g73ykQkGCnI). Accessed 8 May 2020.

Brach T (2020) Radical Compassion: Learning to Love Yourself and Your World with the Practice of RAIN. Ebury: United Kingdom.

Bryant FB, Veroff J (2007) Savoring: A New Model of Positive Experience. Lawrence Erlbaum Associates: Mahwah, NJ.

Center for Mindful Self-Compassion (CMSC). Guided Meditations and Exercises (https:/ / centerformsc.org/ practice-msc/guided-meditations-and-exercises/). Accessed 8 May 2020.

Chernoff P, Adedokun C, O'Sullivan I, McManus J, Payne A (2018) Burnout in the emergency department hospital staff at Cork University Hospital. Irish Journal of Medical Science 188, 667-674.

Chua SE, Cheung V, Cheung C, McAlonan GM, Wong JW, Cheung EP, Chan MT, Wong MM, Tang SW, Choy KM, Wong MK (2004) Psychological effects of the SARS outbreak in Hong Kong on high-risk health care workers. The Canadian Journal of Psychiatry 49, 391-393.

Ducar DM, Penberthy JK, Schorling JB, Leavell VA, Calland JF (2020) Mindfulness for healthcare providers fosters professional quality of life and mindful attention among emergency medical technicians. Explore: The Journal of Science \& Healing 16, 61-68.

Emmons RA, McCullough ME (2003) Counting blessings versus burdens: an experimental investigation of gratitude and subjective well-being in daily life. Journal of Personality and Social Psychology 84, 377.

Gardner PJ, Moallef P (2015) Psychological impact on SARS survivors: critical review of the English language literature. Canadian Psychology 56, 123-135.

Germer CK, Neff KD (2013) Self-compassion in clinical practice. Journal of Clinical Psychology 69, 856-867.

Gilbert P (2005) Compassion and cruelty: a biopsychosocial approach. In Compassion: Conceptualisations, Research and Use in Psychotherapy (ed. P. Gilbert), pp. 9-74. Routledge: New York.

Gilbert P (2010) Training Our Minds in, with and for Compassion: An Introduction to Concepts and 
Compassion-Focused Exercises (https://www.getselfhelp. co.uk/docs/GILBERT-COMPASSION-HANDOUT.pdf). Accessed 21 March 2020.

Greater Good Science Center. Greater Good in Action (https://ggia.berkeley.edu/practice/savoring_walk). Accessed 8 May 2020.

Halifax J (2012) A heuristic model of enactive compassion. Current Opinion in Supportive and Palliative Care 6, 228-235.

Halifax J (2020) 21 March. (https:/ / twitter.com/jhalifax/ status/1241209272567881728). Accessed 21 March 2020.

Irving JA, Dobkin PL, Park J (2009) Cultivating mindfulness in health care professionals: a review of empirical studies of mindfulness-based stress reduction (MBSR). Complementary Therapies in Clinical Practice 15, 61-66.

Ji D, Ji YJ, Duan XZ, Li WG, Sun ZQ, Song XA, Meng YH, Tang HM, Chu F, Niu XX, Chen GF (2017) Prevalence of psychological symptoms among Ebola survivors and healthcare workers during the 2014-2015 Ebola outbreak in Sierra Leone: a cross-sectional study. Oncotarget 8, 12784.

Kabat-Zinn J (1990) Full Catastrophe Living: Using the Wisdom of Your Body and Mind to Face Stress, Pain and Illness. Delacorte Press: New York.

Kabat-Zinn J (2003) Mindfulness-based interventions in context: past, present, and future. Clinical Psychology: Science and Practice 10, 144-156.

Keogh M, O'Doherty V, Trimble T, Hedderman E (2019) Cultivate your inner resilience: an evaluation of a four week course on mindful self-compassion [PowerPoint presentation]. The European Society for Child and Adolescent Psychiatry (ESCAP) International Congress. Vienna.

Khalid I, Khalid TJ, Qabajah MR, Barnard AG, Qushmaq IA (2016) Healthcare workers' emotions, perceived stressors and coping strategies during a MERS-CoV outbreak. Clinical Medicine \& Research 14, 7-14.

Kinser P, Braun S, Deeb G, Carrico C, Dow A (2016)

"Awareness is the first step": an interprofessional course on mindfulness \& mindful-movement for healthcare professionals and students. Complementary Therapies in Clinical Practice 25, 18-25.

Lai J, Ma S, Wang Y, Cai Z, Hu J, Wei N, Wu J, Du H, Chen T, Li R, Tan H (2020) Factors associated with mental health outcomes among health care workers exposed to coronavirus disease. JAMA Network Open 3, e203976-e203976.

Leary MR, Tate EB, Adams CE, Batts Allen A, Hancock J (2007) Self-compassion and reactions to unpleasant self-relevant events: the implications of treating oneself kindly. Journal of Personality and Social Psychology 92, 887.

Lehmann M, Bruenahl CA, Löwe B, Addo MM, Schmiedel S, Lohse AW, Schramm C (2015) Ebola and psychological stress of health care professionals. Emerging Infectious Diseases 21, 913.

Lomas T, Medina JC, Ivtzan I, Rupprecht S, Eiroa-Orosa FJ (2018) A systematic review and meta-analysis of the impact of mindfulness-based interventions on the wellbeing of healthcare professionals. Mindfulness, 1-24. doi: 10.1007/s12671-018-1062-5.

McGehee P, Germer C, Neff K (2017) Core values in mindful self-compassion. In Practitioner's Guide to Ethics and Mindfulness-Based Intervention (ed. L. Monteiro, J.F. Compson, F. Musten), pp. 279-293. Springer: New York.

Neff K (2003) Self-compassion: an alternative conceptualization of a healthy attitude toward oneself. Self and Identity 2, 85-101.

Neff KD, Germer CK (2013) A pilot study and randomized controlled trial of the mindful self-compassion program. Journal of Clinical Psychology 69, 28-44.

O'Leary K, Dockray S (2015) The effects of two novel gratitude and mindfulness interventions on well-being. The Journal of Alternative and Complementary Medicine 21, 243-245.

Ruotsalainen JH, Verbeek JH, Mariné A, Serra C (2014) Preventing occupational stress in healthcare workers. Cochrane Database of Systematic Reviews 11. doi: 10.1002/ 14651858.CD002892.pub5.

Segal ZV, Williams JMG, Teasdale JD (2002) MindfulnessBased Cognitive Therapy for Depression: A New Approach to Preventing Relapse. Guilford: New York.

Shapiro SL, Brown KW, Biegel GM (2007) Teaching selfcare to caregivers: effects of mindfulness-based stress reduction on the mental health of therapists in training. Training and Education in Professional Psychology 1, 105.

Sirois FM, Wood AM (2017) Gratitude uniquely predicts lower depression in chronic illness populations: a longitudinal study of inflammatory bowel disease and arthritis. Health Psychology 36, 122.

Thompson I, Amatea E, Thompson E (2014) Personal and contextual predictors of mental health counselors' compassion fatigue and burnout. Journal of Mental Health Counseling 36, 58-77.

Wasson RS, Barratt C, O'Brien WH (2020) Effects of mindfulness-based interventions on self-compassion in health care professionals: a meta-analysis. Mindfulness, 1-21. doi: 10.1007/s12671-020-01342-5.

Wood AM, Froh JJ, Geraghty AW (2010) Gratitude and well-being: a review and theoretical integration. Clinical Psychology Review 30, 890-905. 